\title{
The role of diagnosis in delirium
}

\section{Introduction}

Delirium is common and is commonly misdiagnosed, chiefly in being missed (Bhat and Rockwood, 2007). The consequences of misdiagnosis are often severe and wide ranging, affecting patients, caregivers, health professionals, and hospitals (Inouye et al., 2014). Many an older hospitalized person with delirium is trapped in the interface between psychiatry and the rest of medicine, and can too easily be caught in the tendentious battles between treating teams. Both researchers and policymakers have sought to improve this unacceptable state of affairs (Young et al., 2010; Tieges et al., 2015).

Healthcare standards not uncommonly stress the importance of prompt diagnosis and staff training and education in achieving this outcome. The narrative of delirium misdiagnosis is thus typically, though not universally, framed as one of under-recognition (Steis and Fick, 2008; Teodorczuk et al., 2012; Yanamadala et al., 2013; Inouye et al., 2014). The implication is that with improved knowledge, improved recognition will follow. Unfortunately, this implication and expectation has not necessarily been borne out.

Although, knowledge of delirium diagnostic criteria is indeed poor amongst nurses (Steis and Fick, 2008) and doctors (Davis and MacLullich, 2009), its association with recognition is not clear. For example, Fick et al. (2007) used the Mary Starke Harper Aging Knowledge Exam (MSHAKE) to determine the relationship between nurses' geropsychiatric knowledge and the responses to the delirium clinical vignettes. The MSHAKE has two questions specific to delirium, one that addresses the acuity of onset and the other its transience and one can score a maximum score of 25 (Santo-Novak et al., 2001). Fick and colleagues found no relationship between nurses' knowledge (mean MSHAKE score 20.4, SD = 2.5) and the responses to the delirium clinical vignettes (Fick et al., 2007). In the study by Davis and MacLullich (2009), 86\% respondents were aware that acute onset was an essential criterion for delirium and almost all agreed that doctors working in acute medical settings should have a good working knowledge of delirium. Importantly, findings of a recent systematic review failed to show that improvement in skills and knowledge alone had a favorable influence on the recognition of delirium (Yanamadala et al., 2013).

Recognition, a relatively passive cognitive act that relies on memory, is necessary but not sufficient for reasoning, which involves forming judgments based on facts and premises. Diagnosis is both a verb and a noun; it refers to the process of diagnosing and the attribution of a diagnosis to the sick person (Kendell, 1975). Thus, doctors arrive at a diagnosis and not simply recognize it. Psychiatric illnesses are defined by their syndromes that are both polythetic and inexact (Kendell, 1975). Despite this, psychiatric illnesses are diagnoses that are products of careful professional examination and "not simply something experienced intuitively or empathically by the examiner" (Kendell, 1975). Misdiagnosis of other categories of illness and disease is characterized in medicine as diagnostic error and not under-recognition. Estimated rates of diagnostic error for medical conditions between $10 \%$ and $15 \%$ are cause of great concern in medicine (Graber, 2013). If delirium were considered a diagnosis, its diagnostic error rate would be an unacceptably high rate of around $70 \%$ (Collins et al., 2010). If we are to remain true to our calling and aim to provide high quality care to elderly, then causes of such error are worthy of examination. To understand why delirium misdiagnosis is often characterized as under-recognition and to improve the care of the elderly affected by delirium, it is important to examine the space that delirium occupies in medicine, that between psychiatry and rest of medicine.

\section{Psychiatry and delirium}

Psychiatric syndromes are useful constructs because "they provide nontrivial information about prognosis and likely treatment outcomes, and/or testable propositions about biological and social correlates" (Kendell and Jablensky, 2003). The evolution of diagnostic criteria in international classificatory systems has seen considerable improvement in the reliability and content validity of discrete psychiatric disorders. While these manuals offer diagnoses with predictive validity, that they 
have limited or no criterion validity (Aboraya et al., 2005 ) is a serious limitation from the point of view of modern medicine because they are not cloaked with scientific respectability.

Psychiatric illnesses are causally complex. Multifactorial causation is the norm. Typically, a psychiatric illness is a product of the interaction between multiple factors including genetics, life experiences and one's agency. To address this, over its history, psychiatry has developed and used many complex casual models from psychoanalysis to the vulnerability-stress model (Zubin and Spring, 1977) to formulate causes in an individual patient. The fact that some of these models have been varyingly amenable to the scientific principle of falsifiability may add to the negativity sometimes attached to the entire discipline of psychiatry (Stuart et al., 2015). Despite such criticisms, the multifactorial model of delirium, which is conceptually similar to the vulnerability-stress model has been used effectively in improving our understanding of delirium (Inouye, 1999).

It is perhaps both this lack of criterion validity and casual complexity that prompted Groopman (2007) to write in his book "How Doctors Think" that trying to assess how psychiatrists think was beyond his abilities. This would have been seen as a remarkable assertion even if it had been made three decades ago, inasmuch as it dismisses psychiatry without recognizing it shares all its basic goals, assumptions and approaches (Leigh, 1982) and the pursuit of offering the best care for its patients, with the rest of medicine. A consequence of such beliefs is that psychiatric diagnostics has often been reduced to a mere task of pattern recognition. This is perhaps most clearly articulated in the development and adoption of structured interview schedules (Spitzer, 1983) which, by definition, dismiss any observation, clinical expertise, or intelligent thinking on the part of the physician.

Diagnosis derives from the Greek word diagignōskein "to distinguish, discern." Discernment is a complex and important thought process, central to good medicine, for the psychiatrist, and the general physician alike. The Concise Oxford Dictionary defines diagnosis as "the identification of the nature of an illness or other problem by examination of symptoms." Diagnostic reasoning is thought to follow two broad approaches: the intuitive/heuristic and the analytical/systematic (Croskerry, 2009). The former approach depends on System 1 reasoning involving inductive logic and heuristics; in contrast the latter approach employs the more effortful System 2 reasoning hypothesis testing and deductive reasoning (Croskerry, 2009). Although, both these approaches rely on recognition, it is the intuitive approach that is recognition primed. Croskerry (2009) has proposed a dual process model of clinical reasoning to better account for reasoning in medicine that occurs under conditions that are typically dynamic, complex, and uncertain.

History taking, physical examination and investigations are the common tools used to arrive at a diagnosis in a given patient. In a prospective study of 442 patients admitted to an internal medicine unit from the emergency department, history was found to be the single most potent tool. In combination with physical examination of the patient, it was diagnostic in $60 \%$ of all admissions (Paley et al., 2011). History and examination are equally important in psychiatry. As with general medical diagnostics, psychiatric diagnostics start with the patient's presenting problems. Unlike general medical diagnostics, however, psychiatry delves deeper into individual experiences with detailed consideration of hypotheses about symptoms, syndromes, and causality. Nuanced analysis and diagnosis of symptoms is particularly important because simple yes/no answers can be misleading (Nordgaard et al., 2013). Structured diagnostic interviews in psychiatry that aim to reduce both information and criterion variance appear to have low agreement with clinical interview (Nordgaard et al., 2012); reductionism is rarely helpful in understanding complex phenomena. Engagement and interview styles will influence what type of clinical information is obtained (Rutter et al., 1981).

Empirical studies of real life interviews suggest that diagnostic decisions are made quite early in the course of an interview (Kendell, 1975). However, in keeping with the dual-process model described earlier (Croskerry, 2009) the interviewer leads on from this initial prototype to modify it with further interactions with the patient (Nordgaard et al., 2013). Experts appear to see and represent a problem at a deeper level often using functional and abstracted representations (Feltovich et al., 2007). Such typifications can be problematic if attempts are not made to falsify. The first author recalls his smugness in putting down an emergency department resident who late on a Friday afternoon was seeking a psychiatric opinion for a 91-yearold female with psychotic symptoms. "Surely?" he said, "she has delirium." Instead of responding with the usual "bloods are normal, the resident said, “...can't be delirium, she scored 29/30 on Standardized Mini-Mental State Examination (SMMSE)"! Occasional bouts of hubris apart, experts often differ from novices in the deployment of meta-cognitive activity and as a result are likely to "fail more gracefully" (Feltovich et al., 2007). The refinement of interview skills in psychiatry with its 
focus on accurate diagnosis of a person's subjective experience should not be seen as being opposed to scientific objectivity (Nordgaard et al., 2013).

To diagnose delirium in older people a thorough knowledge of both interviewing skills and cognitive examination skills is imperative. Interview skills, interpersonal skills, and communication skills are not identical (Ohm et al., 2013). Most medical training programs are not explicit about which of these skills is actively taught. Moreover, while most medical schools have implemented teaching programs in communications skills (Novack et al., 1993), students and practicing physicians in USA, Canada, \& the UK were reported to have deficient or ineffective skills in communication (Keifenheim et al., 2015). Regardless of what is taught, there is evidence that while interventions are successful in improving interactional skills, such gains are short-term and not sustained in the long term (Engler et al., 1981; Craig, 1992). Cognitive examination skills too may not be well taught. In a study of emergency settings, a majority of emergency physicians identified cognitive screening as important but a third believed they lacked the expertise to conduct a cognitive screen (Kennelly et al., 2013).

Psychiatry has refined the art of interviewing. It needs to shed a sense of inadequacy of being viewed poorly by others (Stuart et al., 2015) and take pride in the way it develops the interviewing skills of trainees. Importantly, it needs to take leadership in helping to teach this central clinical skill to the rest of medicine and the medical students of tomorrow.

\section{Medicine and delirium}

General medicine has much to teach psychiatry about the nature of diagnostic errors. The most common framework of aetiology of diagnostic errors divides errors into those caused by systems and those of cognitive origin. Graber et al. (2005) propose the following taxonomy: no-fault errors; system-related errors and; cognitive errors. Nofault errors refer to errors that relate to either the disease or the patient. Disease presentation may be masked or uncommon and patients may be uncooperative or at times, uncommonly, even deceptive. System-related errors as they apply to diagnostics can be due to equipment problems or organizational flaws. Medical decision making often occurs under suboptimal conditions where staff are hurried, distracted, fatigued, sleep deprived, and limited by resource constraints with a workload that is dynamic (Croskerry, 2009). Cognitive errors are understood to occur due to faulty knowledge; faulty data gathering or faulty synthesis. Despite attempts to simplify and classify diagnostic errors, it is clear that errors are commonly multifactorial in origin with interwoven, interacting and inseparable cognitive-system factors (Schiff, 2014).

Older adults constitute $12 \%$ to $24 \%$ of all emergency departments (ED) visits (Samaras et al., 2010). All three elements of Graber's taxonomy no fault, system, and cognitive factors - contribute to errors in diagnosing delirium in this population. Confused older adults are likely to give inadequate information of their condition increasing the likelihood of "no-fault" errors. In Ireland, more than a third of older adults are likely to present to ED unaccompanied (Fealy et al., 2012). In Australia, up to $2.5 \%$ are likely to have been transferred from residential aged care facilities (Arendts and Howard, 2010). Information transfer could be critical (Cortes et al., 2004).

From the time of presentation to a hospital, systemic factors start playing a role. EDs are places for treating acute illnesses and injuries. There is considerable time pressure for fast diagnosis (Hwang and Morrison, 2007). A number of studies have shown that while decisions to admit are made on need such as a high rating on a triage scale, about a third of the discharged older adults had similar physical and mental health characteristics as those admitted (Naughton et al., 2011; Hominick et al., 2016). In addition, typical ED design and space are rarely conducive for managing older adults with co-morbidities. Whereas in ED settings psychiatric interviews may last from 1 to 2 hours (Stebbins and Hardman, 1993), emergency physicians spend considerably less time per consultation (Dale et al., 2008). One may not need 2 hours to arrive at a delirium diagnosis but interviewing needs adequate time especially in an older person. Time pressures and dynamic workloads reduce the likelihood of thorough and effective interviews which undermines the possibility for effective decision-making.

In hospital settings, traditionally used to treat acute or severe conditions that often present as emergencies, efficiency is critical and parsimonious reasoning helps narrow down the most likely cause of the presenting problem and thus may help prevent catastrophic outcomes. Speed and parsimony are less helpful when people present with multiple symptoms, multiple illnesses and multiple causal factors, all of which are the norm with older people rather than the exception (Kroenke, 2014). A recent study conducting a post-hoc analysis of errors made by resident physicians under experimental conditions suggested that one such potential mechanism might be the influence of "salient distracting features" (SDFs) (Mamede et al., 2014). There was a significant interaction 
effect between SDFs and case complexity (Mamede et al., 2014). Distraction by SDFs may be more pronounced in older physicians (Eva and Cunnington, 2006; Mamede et al., 2010). Eschewing the need to spend time with elderly patients to gather an adequate history leads to cognitive errors due to data gathering and data synthesis. For medical diagnoses such errors are more common than errors due to inadequate knowledge (Graber et al., 2005); there is little reason to assume that knowledge errors are more responsible for delirium diagnostic errors.

Physical examination too is important in the diagnosis of delirium. For example, infection is a common precipitant for delirium. It is well documented that infections in older adults, may not present with fever or abnormal investigations. Patients must be examined to detect evidence of infections. There is sound evidence that history and physical examination contribute substantially to a correct diagnosis (Paley et al., 2011). However, one long term retrospective study over four decades shows a decline in junior hospital doctors' admission record suggestive of deterioration in their physical examination skills (Oliver et al., 2013).

Investigations may be relevant in identifying, or excluding, potential causes of delirium in the elderly. However, physicians tend to overemphasize the importance of diagnostic testing, perhaps believing that diagnostic tests are more accurate than historical items and examination findings (Halkin et al., 1998). In the case of delirium, the presence or absence of obvious medical aetiology may influence decision to diagnose delirium as delirium only when no clear aetiology exists (Cheung et al., 2008).

In becoming a team enterprise, medicine has expanded its focus from one patient to many. With this change has come the need to improve patient safety in hospital systems. We need to use its developing tools of enquiry into such systems and its errors such as diagnostic errors and apply them to one of the great tragedies of modern medicine - the under- and missed delirium diagnosis in elderly in hospitals. For this medicine needs to consider delirium as a genuine diagnosis, which when correctly made results in reduced suffering and avoids iatrogenic morbidity.

\section{Looking forward}

Exposure to swans and geese plays an essential role in learning to recognize ducks (Kuhn, 1993).

Diagnostic errors are likely to have more complex causation than medication errors. Medication errors are frequent (Tam et al., 2005) with at least one error detected in two-thirds of patients at admission (Belda-Rustarazo et al., 2015). Non-mandatory teaching activities and checklist implementation were ineffective in reducing medication reconciliation errors (Lea et al., 2016). So, we must be cautious before considering similar solutions for the complex problem of delirium diagnostic error, as some have suggested. As with the prevention and treatment of delirium, multicomponent interventions need to be thought about and explored.

The occurrence and the effect of no-fault factors and systemic factors in delirium diagnostic error in the elderly needs to be recognized and remediated by administrators and policymakers. Some potential solutions relate to the broader issue of care of the elderly and are not specific to delirium, which is, however, important in its own right.

Solutions are often complex and would require a review and rethinking of delivery of healthcare. For example, in the case of correct diagnosis of delirium no-fault diagnostic errors could be minimized with better information transfer in those elderly patients being transferred from nursing homes (Cortes et al., 2004; Arendts and Howard, 2010). Systems factors have been addressed by proposing geriatric EDs (Hwang and Morrison, 2007) and/or a redesign of ED facilities and procedures for frail older adults (Silvester et al., 2014). Consideration for pre-operative comprehensive geriatric assessments could be given as thoughtful pre-operative assessment is associated with improved post-operative outcomes for the elderly (Partridge et al., 2014b). Partridge and colleagues found that despite this clear finding, the majority of existing services remain reactive and do not use comprehensive geriatric assessment as an organizing principle (Partridge et al., 2014a). Similarly, post-operative admission of elderly patients with hip-fracture to a dedicated geriatric unit was associated with reduced mortality and improved walking ability (Boddaert et al., 2014) than when admitted to a general surgical ward. While, changes to healthcare systems that facilitate the assessment and management of the elderly are important, we believe that deeper thinking into the nature of medical and nursing training is necessary for finding solutions for improved healthcare for the geriatric population.

Yanamadala et al. (2013) used the Predisposing, Reinforcing, and Enabling Constructs in Educational Diagnosis and Evaluation (PRECEDE) model in their systematic review. They classified educational interventions into four types depending on the nature of the intervention, i.e., whether they were didactic; whether they facilitated change 
in performance by providing; reinforced learning through reminders and feedback or; were a combination of all three. 20 of the 26 included studies were either Type I (typically involving didactic teaching sessions or workshops) or Type II interventions (typically involving education sessions with assessment tools and protocols for practice). Most of these Type I and Type II interventions did not report on patient care outcomes or change in practice. Moreover, many interventions classified were of short duration. As mentioned previously, studies of interviewing skills suggest that shortterm interventions are unlikely to sustain longterm change in practice (Engler et al., 1981; Craig, 1992). So, in the case of educational interventions to improve delirium recognition, the combination of limited outcomes measured and short duration make it hard to judge whether these interventions resulted in (1) behavior change and improved diagnosis and (2) whether the knowledge, behavior change, and improved diagnosis persisted over time.

The medical interview is the most common task performed by physicians. Engel and Morgan (1973) have called it "the most powerful and sensitive and most versatile instrument available to the physician" (quoted in Keifenheim et al., 2015). This wisdom is being overlooked in the search for gold standards that do not yet exist in much of medicine. The clinical interview is considered an important nursing skill. For example, the Nursing and Midwifery Board of Australia expects a nurse to use "a range of data-gathering techniques, including observation, interview, physical examination, and measurement in obtaining a nursing history and assessment" (Nursing and Midwifery Board of Australia, 2016). Despite its importance, interviewing skills, especially when the focus is on the mind of another person, it can be seen as something not to do with our core work as health professionals. Medicine and medical training must revisit mindbody divisiveness and its pitfalls, and develop ways to consciously avoid mind-body dualism. Without such attention, this dualism and its implication that anything to do with the mind is the exclusive domain of psychiatry rather than part of the clinical practice of all physicians means patients will be continue to be misunderstood and misdiagnosed.

Medicine and nursing must return to the fundamental, which is to focus on the patient. It is thought that in the course of his or her professional life, a clinician will conduct between 100,000 and 200,000 patient interviews (quoted in Keifenheim et al., 2015). A skill so commonly deployed needs to be valued and a closer examination of how skill in interviewing a patient develops is needed. While the use of objective assessment techniques to assess competencies in nursing training have increased (Cant et al., 2013), Tiwari et al. (2005) found that nursing students' adopted a surface approach to learning and focused on preparing for the assessment tasks to the detriment of their learning rather than to value the development of their skills and experience in interviewing and history taking. Deeper learning must be engendered. The knowledge, skills, and techniques for doctoring and nursing then need to evolve to better meet the needs of high number of older adults who present with multiple physical and mental symptoms as well as multiple illnesses who present needing nursing and medical care. Psychiatry and geriatrics, disciplines that pride themselves as medical specialities "with a persistent interest in the patient as a person in an era increasingly dominated by organ-based medical subspecialities," must take the lead (Eisenberg, 2000; Rockwood and Mitnitski, 2011).

The way forward will not be a simple matter of teaching nurses how to evaluate attention or teaching doctors how to ask for collateral information from families. Or, for that matter, conducting more workshops. It will have to be far more ambitious. To be taken seriously, the undervalued art of interviewing has to be transformed into the science of interviewing. It should be taught and evaluated systematically through the entire duration of training for doctors and nurses. Expertise acquisition requires many hours of deliberate practice (Ericsson, 2008). Teaching methods from specialities such as neurology, geriatrics, and psychiatry will have much to contribute. Physicians underestimate the impact of examination findings when estimating conditional probabilities (Herrle et al., 2011), so Nicholl and Appleton have condensed the history and physical examination skills required for expertise in neurology training (Nicholl and Appleton, 2015). In older adults comprehensive geriatric assessment that considers a variety of problems is associated with better outcomes (Ellis et al., 2011). Psychiatric teaching focuses on acquiring expertise in history taking, accurate observation, and mental state examination, and in the words of McHugh and Slavney (2000) "to help trainees become both broad- and tough-minded."

Methods to teach interviewing skills have evolved over time. Observed interviews, videotaped interviews with feedback, role-playing have all shown promise (Shea and Barney, 2015). Developing technologies could also be usefully applied. For example, Ericsson argues that training doctors outside the constraints of everyday encounters with patients can be more effective in enhancing their performance because of the difference between 
deliberate and actual practice (Ericsson, 2014). Video libraries and simulators could be used to attain expertise in performing specific skills as part of the trainees' study methods. Although technology can be effective, we must be cautious for they can also lead to cynicism in contrasting between an idealized "ivory tower" state and a presumed "real world" one. There is no substitute for experience with real patients in live contexts, or for observation of and discussion with more experienced senior colleagues. Perhaps the better call to action is to expose trainees to good role models, and to do so early and commonly. Especially at the beginning of training, future nurses and doctors usually can both tell the difference and appreciate the more humane and more physicianly approach.

\section{Conflict of interest}

None.

\section{Acknowledgment}

Ravi Bhat would like to acknowledge Dr Julie Stone's valuable critique of the initial draft.

\section{RAVI S. BHAT ${ }^{1}$ AND KENNETH ROCKWOOD ${ }^{2}$}

${ }^{1}$ Department of Rural Health, The University of Melbourne, Shepparton, Victoria, Australia

${ }^{2}$ Department of Medicine, Dalhousie University, Halifax, Nova Scotia, Canada

Email: rbhat@unimelb.edu.au

\section{References}

Aboraya, A., France, C., Young, J., Curci, K. and Lepage, J. (2005). The validity of psychiatric diagnosis revisited: the clinician's guide to improve the validity of psychiatric diagnosis. Psychiatry (Edgmont), 2, 48-55.

Arendts, G. and Howard, K. (2010). The interface between residential aged care and the emergency department: a systematic review. Age Ageing, 39, 306-312.

Belda-Rustarazo, S., Cantero-Hinojosa, J., SalmeronGarcia, A., Gonzalez-Garcia, L., Cabeza-Barrera, J. and Galvez, J. (2015). Medication reconciliation at admission and discharge: an analysis of prevalence and associated risk factors. International fournal of Clinical Practice, 69, 1268-1274.

Bhat, R. and Rockwood, K. (2007). Delirium as a disorder of consciousness. Fournal of Neurology Neurosurg Psychiatry, 78, 1167-1170.

Boddaert, J. et al. (2014). Postoperative admission to a dedicated geriatric unit decreases mortality in elderly patients with hip fracture. PLoS One, 9, e83795.

Cant, R., McKenna, L. and Cooper, S. (2013). Assessing preregistration nursing students' clinical competence: a systematic review of objective measures. International fournal of Nursing Practice, 19, 163-176.

Cheung, C. Z. et al. (2008). Recognition and labeling of delirium symptoms by intensivists: does it matter? Intensive Care Medicine, 34, 437-446.

Collins, N., Blanchard, M. R., Tookman, A. and Sampson, E. L. (2010). Detection of delirium in the acute hospital. Age Ageing, 39, 131-135.

Cortes, T. A., Wexler, S. and Fitzpatrick, J. J. (2004). The transition of elderly patients between hospitals and nursing homes. Improving nurse-to-nurse communication. fournal of Gerontological Nursing, 30, 10-15, quiz 52-13.

Craig, J. L. (1992). Retention of interviewing skills learned by first-year medical students: a longitudinal study. Medical Education, 26, 276-281.

Croskerry, P. (2009). A universal model of diagnostic reasoning. Academic Medicine, 84, 1022-1028.

Dale, J., Sandhu, H., Lall, R. and Glucksman, E. (2008). The patient, the doctor and the emergency department: a cross-sectional study of patient-centredness in 1990 and 2005. Patient Education and Counseling, 72, 320-329.

Davis, D. and MacLullich, A. (2009). Understanding barriers to delirium care: a multicentre survey of knowledge and attitudes amongst UK junior doctors. Age Ageing, 38, 559-563.

Eisenberg, L. (2000). Is psychiatry more mindful or brainier than it was a decade ago? British fournal of Psychiatry, 176, $1-5$.

Ellis, G., Whitehead, M. A., Robinson, D., O'Neill, D. and Langhorne, P. (2011). Comprehensive geriatric assessment for older adults admitted to hospital: meta-analysis of randomised controlled trials. Bmj: British Medical fournal, 343, d6553.

Engel, G. L. and Morgan, W. L. (1973). Interviewing the patient: WB Saunders Company.

Engler, C. M., Saltzman, G. A., Walker, M. L. and Wolf, F. M. (1981). Medical student acquisition and retention of communication and interviewing skills. Fournal of Medical Education, 56, 572-579.

Ericsson, K. A. (2008). Deliberate practice and acquisition of expert performance: a general overview. Academic Emergency Medicine, 15, 988-994.

Ericsson, K. A. (2014). Necessity is the mother of invention: video recording firsthand perspectives of critical medical procedures to make simulated training more effective. Academic Medicine, 89, 17-20.

Eva, K. W. and Cunnington, J. P. (2006). The difficulty with experience: does practice increase susceptibility to premature closure? Fournal of Continuing Education in the Health Professions, 26, 192-198.

Fealy, G. M., Treacy, M., Drennan, J., Naughton, C., Butler, M. and Lyons, I. (2012). A profile of older emergency department attendees: findings from an Irish study. Fournal of Advanced Nursing, 68, 1003-1013.

Feltovich, P. J., Prietula, M. J. and Ericsson, K. A. (2007). Studies of expertise from psychological perspectives. In K. A. Ericsson, N. Charness, P. J. Feltovich and R. R. Hoffman (eds)., The Cambridge Handbook of Expertise and Expert Performance (Chapter 4, pp. 41-67). Cambridge: Cambridge University Press.

Fick, D. M., Hodo, D. M., Lawrence, F. and Inouye, S. K. (2007). Recognizing delirium superimposed on 
dementia: assessing nurses' knowledge using case vignettes. fournal of Gerontological Nursing, 33, 40-47, quiz 48-49.

Graber, M. L. (2013). The incidence of diagnostic error in medicine. BMF Quality and Safety, 22(Suppl. 2), ii21-ii27.

Graber, M. L., Franklin, N. and Gordon, R. (2005). Diagnostic error in internal medicine. Archives of International Medicine, 165, 1493-1499.

Groopman, J. (2007). How Doctors Think (p. 7). Carlton North: Scribe Publications Pty Ltd.

Halkin, A., Reichman, J., Schwaber, M., Paltiel, O. and Brezis, M. (1998). Likelihood ratios: getting diagnostic testing into perspective. Qjm, 91, 247-258.

Herrle, S. R., Corbett, E. C. Jr., Fagan, M. J., Moore, C. G. and Elnicki, D. M. (2011). Bayes' theorem and the physical examination: probability assessment and diagnostic decision making. Academic Medicine, 86, 618-627.

Hominick, K., McLeod, V. and Rockwood, K. (2016). Characteristics of older adults admitted to hospital versus those discharged home, in emergency department patients referred to internal medicine. Canadian Geriatrics fournal, 19, 9-14.

Hwang, U. and Morrison, R. S. (2007). The geriatric emergency department. Fournal of the American Geriatrics Society, 55, 1873-1876.

Inouye, S. K. (1999). Predisposing and precipitating factors for delirium in hospitalized older patients. Dementia and Geriatric Cognitive Disorders, 10, 393-400.

Inouye, S. K., Westendorp, R. G. and Saczynski, J. S. (2014). Delirium in elderly people. Lancet, 383, 911-922.

Keifenheim, K. E. et al. (2015). Teaching history taking to medical students: a systematic review. BMC Medical Education, 15, 159.

Kendell, R. and Jablensky, A. (2003). Distinguishing between the validity and utility of psychiatric diagnoses. American fournal Psychiatry, 160, 4-12.

Kendell, R. E. (1975). The Role of Diagnosis in Psychiatry (pp. 9-26). Oxford: Blackwell Scientific Publications.

Kennelly, S. P., Morley, D., Coughlan, T., Collins, R., Rochford, M. and O'Neill, D. (2013). Knowledge, skills and attitudes of doctors towards assessing cognition in older patients in the emergency department. Postgraduate Medical fournal, 89, 137-141.

Kroenke, K. (2014). A practical and evidence-based approach to common symptoms: a narrative review. Annals International Medicine, 161, 579-586.

Kuhn, T. S. (1993). Metaphor in science. In A. Ortony (ed.), Metaphor and Thought (2nd ed., pp. 409-419). Cambridge: Cambridge University Press.

Lea, M., Barstad, I., Mathiesen, L., Mowe, M. and Molden, E. (2016). Effect of teaching and checklist implementation on accuracy of medication history recording at hospital admission. International fournal of Clinical Pharmacy, 38, 20-24.

Leigh, H. (1982). Comment: the role of psychiatry in medicine. American Fournal of Psychiatry, 139, 1581-1587.

Mamede, S. et al. (2010). Effect of availability bias and reflective reasoning on diagnostic accuracy among internal medicine residents. $\mathcal{F A M A}, 304,1198-1203$.

Mamede, S., van Gog, T., van den Berge, K., van Saase, J. L. and Schmidt, H. G. (2014). Why do doctors make mistakes? A study of the role of salient distracting clinical features. Academic Medicine, 89, 114-120.

McHugh, P. and Slavney, P. R. (2000). The education of psychiatrists. In M. G. Gelder, J. J. Lopez-Ibor and N. Andreasen (eds.), New Oxford Textbook of Psychiatry (Chapter 1.7, pp. 41-47). Oxford: Oxford University Press.

Naughton, C. et al. (2011). How different are older people discharged from emergency departments compared with those admitted to hospital? European fournal of Emergency Medicine, 18, 19-24.

Nicholl, D. J. and Appleton, J. P. (2015). Clinical neurology: why this still matters in the 21 st century. Fournal of Neurology, Neurosurgery Psychiatry, 86, 229-233.

Nordgaard, J., Revsbech, R., Saebye, D. and Parnas, J. (2012). Assessing the diagnostic validity of a structured psychiatric interview in a first-admission hospital sample. World Psychiatry, 11, 181-185.

Nordgaard, J., Sass, L. A. and Parnas, J. (2013). The psychiatric interview: validity, structure, and subjectivity. European Archives of Psychiatry and Clinical Neurosciences, 263, 353-364.

Novack, D. H., Volk, G., Drossman, D. A. and Lipkin, M. Jr. (1993). Medical interviewing and interpersonal skills teaching in US medical schools. Progress, problems, and promise. Fama: Fournal of the American Medical Association, 269, 2101-2105.

Nursing and Midwifery Board of Australia (2016). Registered nurse standards for practice. Available at: http:/www.nursingmidwiferyboard.gov.au/ Codes-Guidelines-Statements/Professional-standards.aspx.

Ohm, F., Vogel, D., Sehner, S., Wijnen-Meijer, M. and Harendza, S. (2013). Details acquired from medical history and patients' experience of empathy-two sides of the same coin. BMC Medical Education, 13, 67.

Oliver, C. M., Hunter, S. A., Ikeda, T. and Galletly, D. C. (2013). Junior doctor skill in the art of physical examination: a retrospective study of the medical admission note over four decades. BMF Open, 3(4). doi: 10.1136/bmjopen-2012-002257

Paley, L., Zornitzki, T., Cohen, J., Friedman, J., Kozak, N. and Schattner, A. (2011). Utility of clinical examination in the diagnosis of emergency department patients admitted to the department of medicine of an academic hospital. Archives of International Medicine, 171, 1394-1396.

Partridge, J. S., Collingridge, G., Gordon, A. L., Martin, F. C., Harari, D. and Dhesi, J. K. (2014a). Where are we in perioperative medicine for older surgical patients? A UK survey of geriatric medicine delivered services in surgery. Age Ageing, 43, 721-724.

Partridge, J. S., Harari, D., Martin, F. C. and Dhesi, J. K. (2014b). The impact of pre-operative comprehensive geriatric assessment on postoperative outcomes in older patients undergoing scheduled surgery: a systematic review. Anaesthesia, 69(Suppl. 1), 8-16.

Rockwood, K. and Mitnitski, A. (2011). Frailty defined by deficit accumulation and geriatric medicine defined by frailty. Clinics in Geriatrics Medicine, 27, 17-26.

Rutter, M., Cox, A., Egert, S., Holbrook, D. and Everitt, B. (1981). Psychiatric interviewing techniques. IV. 
Experimental study: four contrasting styles. British fournal of Psychiatry, 138, 456-465.

Samaras, N., Chevalley, T., Samaras, D. and Gold, G. (2010). Older patients in the emergency department: a review. Annals of Emergency Medicine, 56, 261-269.

Santo-Novak, D. A., Duncan, J. W., Grissom, K. R. and Powers, R. E. (2001). MSHAKE. A tool for measuring staff knowledge related to geriatric mental health. Fournal of Gerontological Nursing, 27, 29-35.

Schiff, G. D. (2014). Diagnosis and diagnostic errors: time for a new paradigm. BMF Quality and Safety, 23, $1-3$.

Shea, S. C. and Barney, C. (2015). Teaching clinical interviewing skills using role-playing: conveying empathy to performing a suicide assessment: a primer for individual role-playing and scripted group role-playing. Psychiatrics Clinics of North America, 38, 147-183.

Silvester, K. M., Mohammed, M. A., Harriman, P., Girolami, A. and Downes, T. W. (2014). Timely care for frail older people referred to hospital improves efficiency and reduces mortality without the need for extra resources. Age Ageing, 43, 472-477.

Spitzer, R. L. (1983). Psychiatric diagnosis: are clinicians still necessary? Comprehensive Psychiatry, 24, 399-411.

Stebbins, L. A. and Hardman, G. L. (1993). A survey of psychiatric consultations at a suburban emergency room. General Hospital Psychiatry, 15, 234-242.

Steis, M. R. and Fick, D. M. (2008). Are nurses recognizing delirium? A systematic review. Fournal of Gerontological Nursing, 34, 40-48.
Stuart, H., Sartorius, N. and Liinamaa, T. (2015). Images of psychiatry and psychiatrists. Acta Psychiatrica Scandinavica, 131, 21-28.

Tam, V. C., Knowles, S. R., Cornish, P. L., Fine, N., Marchesano, R. and Etchells, E. E. (2005). Frequency, type and clinical importance of medication history errors at admission to hospital: a systematic review. Cmaj, 173, 510-515.

Teodorczuk, A., Reynish, E. and Milisen, K. (2012). Improving recognition of delirium in clinical practice: a call for action. BMC Geriatrics, 12, 55.

Tieges, Z. et al. (2015). Development of a smartphone application for the objective detection of attentional deficits in delirium. International Psychogeriatrics, 27, 1251-1262.

Tiwari, A., Lam, D., Yuen, K. H., Chan, R., Fung, T. and Chan, S. (2005). Student learning in clinical nursing education: perceptions of the relationship between assessment and learning. Nurse Education Today, 25, 299-308.

Yanamadala, M., Wieland, D. and Heflin, M. T. (2013). Educational interventions to improve recognition of delirium: a systematic review. Fournal of the American Geriatrics Society, 61, 1983-1993.

Young, J., Murthy, L., Westby, M., Akunne, A. and O'Mahony, R. (2010). Diagnosis, prevention, and management of delirium: summary of NICE guidance. BMF, 341, c3704.

Zubin, J. and Spring, B. (1977). Vulnerability-a new view of schizophrenia. Fournal of Abnormal Psychology, 86, 103-126. 